\title{
Intraspecific invasion occurring in geographically isolated populations of the Japanese cyprinid fish Zacco platypus
}

\author{
Kenzi Takamura $^{1} \cdot$ Mayuko Nakahara $^{1}$
}

Received: 30 October 2014/Accepted: 21 March 2015/Published online: 8 April 2015

(c) The Author(s) 2015. This article is published with open access at Springerlink.com

\begin{abstract}
Geographically isolated populations of freshwater fish have been introduced into conspecific native populations. One of the most representative cases is the pale chub Zacco platypus. The pale chub of Lake Biwa in western Japan has been inadvertently introduced to other waters with the release of game fish. Because they are not clearly discriminated from other populations by their morphological characteristics, the morphological detection of the colonization is not possible. Hence, a genetic analysis of fish collected from rivers of the Kanto Plain in eastern Japan, where the introduction was made, was conducted. The haplotype variety of the mitochondrial gene cytochrome $b$ of the fish revealed the presence of two major groups of haplotypes. We concluded that one of the groups was introduced from western Japan, especially Lake Biwa, and the other was native to the Kanto Plain. The haplotypes from western Japan were established in all of the rivers studied and occurred together with the native haplotypes in the rivers within the original distribution range of the species. The allelic composition of microsatellite loci indicated that fish from the two different sources were well admixed through hybridization in the populations of the rivers of the Kanto Plain.
\end{abstract}

Keywords Hybridization - Inadvertent introduction . Lake Biwa · The Kanto Plain · Phylogroup

Handling Editor: Yoshinori Taniguchi.

Electronic supplementary material The online version of this article (doi:10.1007/s10201-015-0450-y) contains supplementary material, which is available to authorized users.

Kenzi Takamura

takaken@nies.go.jp

1 National Institute for Environmental Studies, 16-2 Onogawa, Tukuba, Ibaraki 305-8506, Japan

\section{Introduction}

Intraspecific invasions occur when introduced organisms belong to a sister species, subspecies, or intraspecific groups, which are defined by prominent genetic gaps in haplotypes [intraspecific phylogroup (Avise 2000)] with any native organisms. The introduced organisms are most likely to interact with the native organisms through competition. One of the other probable interactions is intraspecific hybridization in which the introduced organisms hybridize with the native organisms and degrade their genetic identity (Allendorf et al. 2001; Bennett et al. 2010).

Fish have been introduced to non-native areas through activities such as fishery, game fishing, ornamental trade, or habitat restoration (Lever 1996; Gozlan et al. 2010). When this introduction occurs where native populations of the same species are present, intraspecific invasion can occur. The resultant situation is often the colonization of the introduced population and/or the hybridization with native populations [e.g., marine bluestriped snapper (Gaither et al. 2010); riverine brown trout (Hansen et al. 2009)]. This colonization has occurred deliberately as a target species and inadvertently as an accompanying species.

In cases of intraspecific invasion, because introduced fish and native fish are similar in their morphological characteristics, these fish are usually hard to distinguish by appearance. Thus, it is difficult to morphologically determine whether the introduced fish are established. Genetic methods, such as genotyping by DNA sequencing, microsatellites, or amplified fragment length polymorphism (AFLP) analysis, are indispensable for the detection of the colonization of introduced fish in the new environment (Hansen et al. 2009; Gaither et al. 2010; Kuwahara et al. 2012; Yokoyama and Yamamoto 2012). 
In Japanese freshwaters, the deliberate introduction of fish species has been frequently undertaken (Ecological Society of Japan 2002; Nature Conservation Committee of Ichthyological Society of Japan 2005). One of the most representative cases is the introduction of the Lake Biwa stock of the ayu fish Plecoglossus altivelis Temminck and Schlegel into other Japanese freshwaters (Miyadi 1962). This introduction has had many effects on Japanese freshwater ecosystems because this introduction has been not only widely undertaken throughout the Japanese islands but also inadvertently accompanied by many other fish species (Kawai et al. 1980; Mizuguchi 1990).

The pale chub Zacco platypus (Temminck and Schlegel) is one of the accompanying species (Mizuguchi 1990). This species lives not only in middle and lower reaches of rivers but also in coastal lake water, where this fish is one of the most abundant fishes (Mizuno et al. 1958; Miyadi et al. 1976). This fish was even introduced into freshwater bodies in Taiwan in association with the release of $P$. altivelis from Lake Biwa (Ma et al. 2006). In the Japanese islands, this fish was originally distributed in the western and eastern parts of Honshu Island, as well as in Kyushu and Shikoku islands (Miyadi et al. 1976). The distribution of this fish is currently up to the northeastern part of Honshu Island (Mizuguchi 1970, 1990; National Land with Water Information Data Management Center 2014). The introduction has occurred both within and outside its original distribution.

The effects of this introduction are not limited to the distribution expansion itself, in the case where this introduced fish originated from Lake Biwa in western Japan. This lake is the largest lake in Japan and has been geographically isolated from eastern Japanese freshwater bodies for approximately 1 million years (Kawabe 1994). Because of this long geographical isolation, a unique fish fauna has evolved. The number of fish species endemic to the lake was reported to be small (11 of the 57 total species) (Mori and Miura 1990); however, an increasing number of genetically isolated local populations have been recorded in the lake system with the recent development of molecular phylogenetic and comparative morphological approaches (Yoshiyasu 1973; Saitoh et al. 2000; Takahashi and Okazaki 2002; Watanabe et al. 2003). Therefore, fish with a different trait set may have been introduced in the face of the originally distributed populations in rivers of eastern Japan.

Hayakawa et al. (2009) performed a phylogenetic analysis of the mitochondrial DNA gene (cytochrome $b$ ) of $Z$. platypus over the Japanese Islands from the north of Honshu Island to Kyushu Island. The following three phylogroups have been recognized: East-Japan (Kanto to Tokai districts), West Japan (Kinki to northeastern part of Kyushu), and Kyushu. Therefore, the introduction of the fish from Lake Biwa to rivers of eastern Japan has crossed the geographical boundary.
Plecoglossus altivelis of Lake Biwa were first released into rivers of eastern Japan in 1913. The amount of release increased after World War II and was sustained for several decades. Although the current release amount has been greatly controlled because of the severe prevalence of the cold water disease by Flavobacterium psychrophilum for the Lake Biwa stock of $P$. altivelis in the 1990s, the release amount was massive during that period. For example, the release during the period from 1955 to 1979 amounted to approximately 44 tons and 36 tons in the Naka and Kinu Rivers in eastern Japan, respectively (Takamura 2013).

The present study aimed to understand (1) whether $Z$. platypus of Lake Biwa were established in rivers of the Kanto Plain, eastern Japan, where a different phylogroup of the same species was natively distributed, and (2) whether these fish hybridize with native fish. The average numbers of vertebrae are higher in the populations of Lake Biwa and in newly established populations from this lake than in other populations (Mizuguchi 1970). However, the ranges of the numbers of vertebrae overlapped between these populations; therefore, this morphological characteristic is not helpful in determining whether the fish introduced from Lake Biwa have been established in rivers of the Kanto Plain. Therfore, molecular phylogenetic approaches were applied.

\section{Materials and methods}

\section{Sample collection}

Adult fish specimens were collected from eight rivers: the Hananuki (HN), Kuji (KJ), Naka (NK), Kinu (KN), Omoi (OM), Tama (TM), and Sagami (SG) Rivers in the Kanto Plain and the Ado River, which flow into Lake Biwa, one of the sources of intraspecific introduction (Fig. 1). Specimens of the Naka and Kinu Rivers were collected at six sites of each river in April to June 2004. Specimens of the other rivers were collected at one site of each river during the same season in 2006 and in 2007. Specimens of the Ado River were collected in June and July 2004. The fish specimens were measured to determine their standard length and body weight, and approximately $50 \mathrm{mg}$ of flesh was sampled from each specimen for genetic analysis.

\section{DNA sequencing}

DNA was extracted from the flesh sample using a QIAGEN DNeasy Blood and Tissue Kit (Qiagen, Germany). The DNA extract was diluted to $50 \mathrm{ng} / \mu \mathrm{l}$ with purified water. The cytochrome $b$ gene of mitochondrial DNA ( $\sim 1193$ bp) was amplified. The primers initially used were LCB1 (5'-AATGACTTGAAGAACCACCGT-3') and HA 


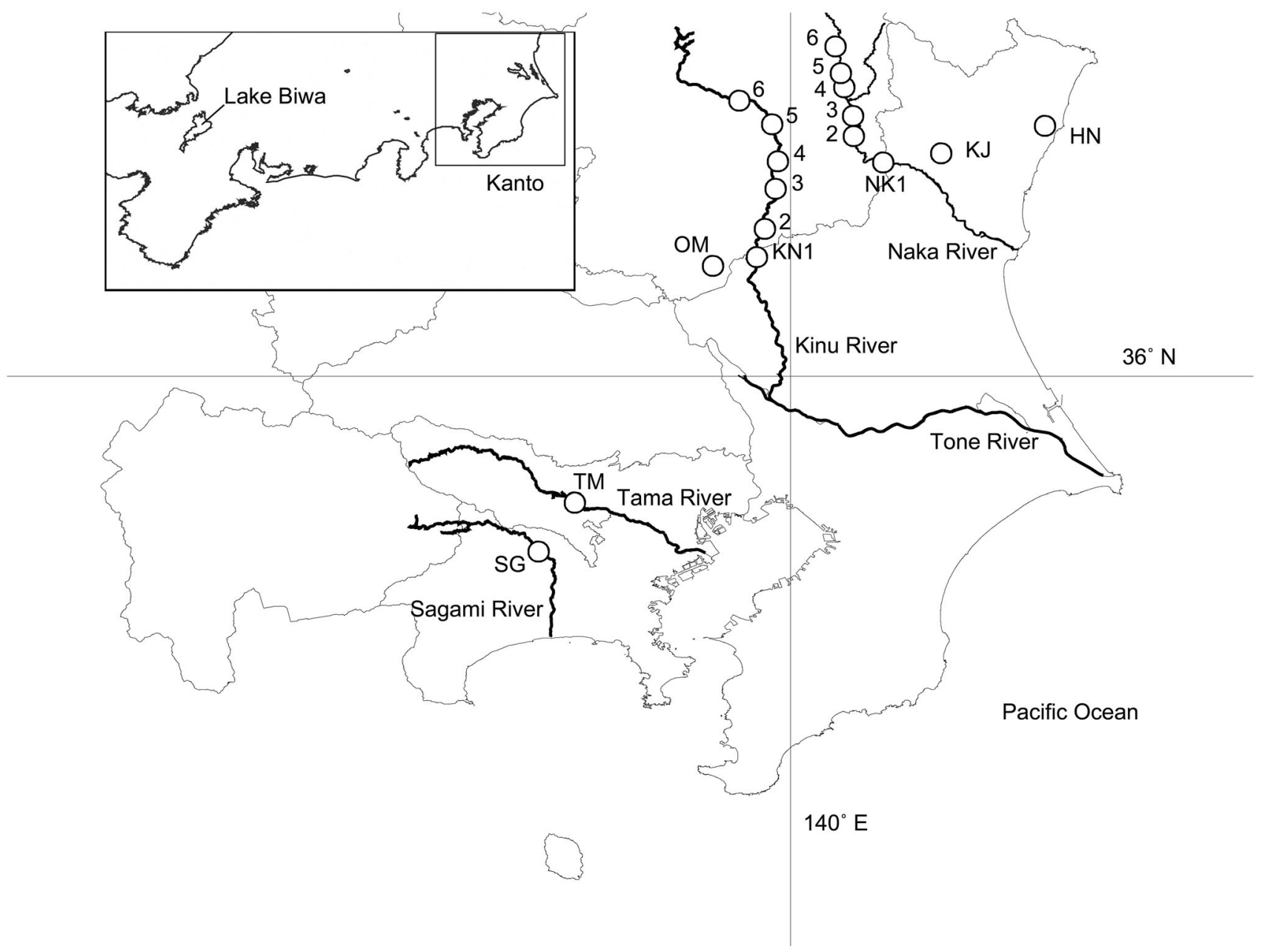

Fig. 1 Map of study sites. Site locations are indicated by open circles. $H K$ Hananuki, $K J$ Kuji, $N K$ Naka, $K N$ Kinu, $O M$ Omoi, $T M$ Tama, SG Sagami; river courses are indicated by thick lines; the

\section{(5'-CAACGATCTCCGGTTTACAAGAC- ${ }^{\prime}$ ) (Perdices}

et al. 2004). Because both ends of the target sequence were not clearly amplified with this first set of primers, an additional set of primers, LCBZp (5'-CCCTCGTGGCAGA CATAGTT- $\left.3^{\prime}\right)$ and HCBZp (5'-GAAGAATGATGCTCCG TTGG- $3^{\prime}$ ), was designed inside the target area from the sequence reads of the first set of primers. PCR amplification was performed in a $50-\mu$ l solution $[1 \times$ ExTaq buffer (Takara, Japan), $0.2 \mathrm{mM}$ of each dNTP, $0.2 \mathrm{U}$ of Ex Taq DNA polymerase (Takara, Japan), $0.5 \mu \mathrm{M}$ of each primer, and $1 \mathrm{ng}$ of template DNA]. The reaction conditions were as described by Perdices et al. (2004).

A portion of the PCR product was loaded onto an agarose gel to confirm the amplification of the target gene. The rest of the product was then used as template DNA for sequencing using an $\mathrm{ABI}$ BigDye Terminator version 3.1 Cycle Sequencing Kit and 3730 DNA Analyzer (Life Technologies, USA), following the manufacturer's protocol. The sequencing results with the four primers were courses of the Hananuki, Kuji, and Omoi Rivers are not shown; thin lines delineate the sea shoreline and prefectural borders. The inset shows the location of Lake Biwa and the Kanto Plain

assembled into the entire region of the gene using the ATGC software (Genetyx Corp., Japan).

\section{Phylogenetic analysis}

For sequencing, up to approximately 30 specimens per site were used from the Kanto Plain (Table 1) and Lake Biwa. The sequences determined for 354 specimens from rivers of the Kanto Plain and 18 specimens from Lake Biwa were aligned using the Clustal W software of the DNA Data Bank Japan (clustalw.ddbj.nig.ac.jp) and assigned to haplotypes. A statistical parsimony network of haplotypes was constructed using the software TCS 1.21 (Clement et al. 2000). Phylogenetic trees were also constructed for the haplotypes. The jModelTest 2 software (Darriba et al. 2012, Guindon and Gascuel 2003) was used to determine the mutational model that fit the haplotype data. The bestfit model was $\operatorname{TrN}+\mathrm{G}$ (Tamura and Nei 1993) according to the Bayesian information criterion and a decision- 
Table 1 Occurrence of mitochondrial cytochrome $b$ gene haplotypes of adult $Z$. platypus in rivers of the Kanto Plain

\begin{tabular}{lllllr}
\hline Site & Total fish & Group I & Group II & Group II (\%) & NOH \\
\hline HN & 7 & 0 & 7 & 100 & $5(1)$ \\
KJ & 13 & 0 & 13 & 100 & $10(6)$ \\
NK1 & 29 & 25 & 4 & 14 & $4(0)$ \\
NK2 & 31 & 23 & 8 & 26 & $7(1)$ \\
NK3 & 21 & 17 & 4 & 19 & $3(0)$ \\
NK4 & 22 & 13 & 9 & 41 & $9(3)$ \\
NK5 & 30 & 20 & 10 & 33 & $10(4)$ \\
NK6 & 30 & 26 & 4 & 13 & $4(0)$ \\
Mean (NK) & & & & 24 & \\
KN1 & 27 & 16 & 11 & 41 & $9(3)$ \\
KN2 & 30 & 17 & 13 & 43 & $11(6)$ \\
KN3 & 30 & 16 & 14 & 47 & $11(3)$ \\
KN4 & 30 & 18 & 12 & 40 & $10(2)$ \\
KN5 & 30 & 20 & 10 & 33 & $8(3)$ \\
KN6 & 5 & 3 & 2 & 40 & 2 \\
Mean (KN) & & & & 41 & $5(1)$ \\
OM & 21 & $10(6)$ & $11(6)$ & 52 & $4(1)$ \\
TM & 32 & $20(15)$ & $12(8)$ & 38 & $2(1)$ \\
SG & 17 & $8(8)$ & $9(7)$ & 53 & \\
\hline Lo & & & & & \\
\end{tabular}

Locations of the sites are shown in Fig. 1. $\mathrm{NOH}$ numbers of the group II haplotypes (haplotypes unique to the site in parentheses). Over half of the fish from OM, TM, and SG were classified to group I or II using the genotyping method. Their numbers are provided in parentheses in the third and fourth columns (groups I and II). These fish are not included in the sixth column $(\mathrm{NOH})$

theoretic performance-based approach. Accordingly, this model was used for the tree construction. The tree construction was performed using the neighbor-joining (NJ), maximum likelihood (ML), maximum parsimony (MP), and Bayesian (Bayes) methods. The NJ, ML, and MP methods were applied using the MEGA 4.0 software (Tamura et al. 2007) with a bootstrap test (1000 replicates) for the reliability of the cluster. The Bayes method was applied using the MrBayes 3.1 program (Huelsenbeck and Ronquist 2001). The reliability of the cluster was evaluated using the posterior probabilities. The GTR + G model was used in this study because this model is the next most complex model following $\operatorname{TrN}+\mathrm{G}$, which is not available in the software. A sequence (DNA Data Bank of Japan, accession no. AF309084) of Nipponocypris temminki (Temminck and Schlegel) was used as an out-group taxon. All of the sequences were trimmed to $1140 \mathrm{bp}$, which is the length of the sequence of $N$. temminki under the complete deletion option. The $P$-distance, which is a simple model of evolutionary distance, is the fraction of sites that differ between a pair of sequences. This distance was estimated using the MEGA software and used to judge the reliability of clusters found in the constructed trees.

\section{Genotyping of haplotype groups}

As mentioned later in the "Results" section, two groups of haplotypes were identified by a phylogenetic analysis of haplotypes. Two sets of primers were designed to determine the haplotype group based on the match and mismatch of primers originally for genotyping a mass collection of larval fish (Takamura 2013). These primers were applied for 50 specimens to increase the sample size from three rivers (OM, TM, and SG). The first set of primers was EJZp-F (5'-ATTTTCCATTTTAGTACTAATA GTT- $\left.3^{\prime}\right)$ and EJZp-R (5'-GCGGGGTTAGAATCAGGAA TAA- $\left.3^{\prime}\right)$, and the second set was WJZp-F (5'-ATTTTCCATTTTAGTACTGATAGTC- $\left.3^{\prime}\right)$ and WJZp-R ( $5^{\prime}$ - GTG GGGTTAGAATCAGGAATAG- $3^{\prime}$ ). The PCR conditions were as follows: initial denaturation at $94{ }^{\circ} \mathrm{C}$ for $300 \mathrm{~s} ; 30$ cycles of denaturation at $94{ }^{\circ} \mathrm{C}$ for $30 \mathrm{~s}$, annealing at $58{ }^{\circ} \mathrm{C}$ for $30 \mathrm{~s}$, extension at $72{ }^{\circ} \mathrm{C}$ for $30 \mathrm{~s}$; and the final extension at $72{ }^{\circ} \mathrm{C}$ for $420 \mathrm{~s}$ for EJZp-F and EJZp-R, as well as an initial denaturation at $94{ }^{\circ} \mathrm{C}$ for $300 \mathrm{~s}$; 30 cycles of denaturation at $94{ }^{\circ} \mathrm{C}$ for $30 \mathrm{~s}$, annealing at $62{ }^{\circ} \mathrm{C}$ for $30 \mathrm{~s}$, extension at $72{ }^{\circ} \mathrm{C}$ for $30 \mathrm{~s}$; and the final extension at $72{ }^{\circ} \mathrm{C}$ for $420 \mathrm{~s}$ for WJZp-F and WJZp-R. The PCR solution was identical to that for DNA sequencing. The major differences between the two sets of primers in the priming site were four transition sites (nos. 927, 933, 1105, and 1125; Table S1). Genotyping was based on the presence/ absence of a band (210 bp) on the agarose gel loaded with the PCR product from the two sets of primers. Reliability was confirmed by applying the method to 20 specimens of each of the haplotype groups (Takamura 2013).

\section{Statistical analysis}

The frequency of haplotype groups was compared between the Naka and Kinu Rivers. The frequencies at six sites from each of the rivers were compared using the Wilcoxon rank sum test. The frequency data were arcsine transformed before the statistical tests were conducted. All statistical tests were performed using the statistical software $\mathrm{R}$ version 2.2.0 (The R Foundation for Statistical Computing 2005).

\section{Population structure analysis}

In a previous study (Takamura 2009), 396 specimens of the 2004 sample from each of six sites of the Naka and Kinu Rivers (5-45 fish per site) were typed for seven microsatellite DNA loci (Z128A, ZD181, ZD366, ZD992, ZD1021, ZD331, and ZD657; Huang et al. 2003) in order to measure the degree of genetic isolation within a river. An additional 21 specimens from the Ado River of Lake Biwa were typed in the present study. These allele 
frequency data were used for population structure analysis in the two rivers. The origin of the sampled fish of each river was inferred from the data using the STRUCTURE 2.2 software (Prichard et al. 2000) under two different models. The first was an admixture model with prior population information that specimens from Lake Biwa have their origin in the lake itself. Another model was without such information, i.e., an admixture model with the assumption of correlated allele frequencies, where all populations may have mixed ancestry. The software was run for 500,000 generations, with a burn-in of 500,000. The most probable number of populations $(K)$ was determined from higher values of mean $\mathrm{Ln} P(D)$, the log likelihood of the posterior probability of the data for a given $K$ (Prichard et al. 2007), and the ad hoc statistic $\Delta K$ (Evanno et al. 2005), which was calculated from 10 independent runs of $K=1-10$. The sample from Lake Biwa was of known origin and was used to classify individuals of unknown origin from the Naka and Kinu Rivers in the admixture model with prior population information. Gene diversities of the samples of the Naka and Kinu Rivers and of Lake Biwa were computed using the Genepop (Raymond and Rousset 1995; Rousset 2008) and Fstat software packages (Goudet 1995).

\section{Results}

In total, 73 haplotypes of the mitochondrial cytochrome $b$ gene were found in 372 specimens (Table S1). These haplotypes were deposited in the DNA Data Bank of Japan (accession nos. AB572354-572402, 572404-572418, and AB734080-734088). Of these haplotypes, 64 were found in specimens of the Kanto Plain, 18 (I01-I18) in specimens of Lake Biwa, and nine (I01-I03, I06, I10, I11, I13-I15) in both areas. The 55 haplotypes H01-H55 were found only in the Kanto Plain. In total, 96 mutation sites were found among the haplotypes (Table S1).

A statistical parsimony network revealed that the haplotypes were divided into two major groups, which were separated by 11 steps: 6 haplotypes (H1-H6) and all other haplotypes (Fig. 2). In the phylogenetic tree construction, the Bayes tree (Fig. 3) and all other NJ, ML, and MP trees (data not shown) constructed for these haplotypes also demonstrated the presence of a cluster of H01-H06. The cluster was supported with probabilities of $100 \%$ (Bayes), $93 \%$ (NJ), $95 \%$ (ML), and $96 \%$ (MP). This cluster was further divided into two subclusters (H01-H04 and H05, H06). In the Bayes tree, the remaining haplotypes were not included in a single major cluster but were divided into four clusters, each with a probability $>50 \%$, and seven other haplotypes. The branches connecting the four clusters and the seven haplotypes were clearly shorter than the branch to the cluster of H01-H06. The $P$-distance was 0.004 on average in the cluster of H01-H06 and 0.006 in the group of other haplotypes; however, the p-distance was 0.017 between the two groups. The net average distance between the groups was 0.012 . The group of 67 haplotypes included all 18 haplotypes from Lake Biwa. These Lake Biwa haplotypes were distributed over the group and were not confined to any of the four clusters. Haplotypes H01-H06 were grouped as group I, and the other haplotypes were grouped as group II.

The evolutionary distance between the two groups, which is a proportion of base substitutions per site, was $1.55 \%$ (ML). The evolutionary rate of $1.52 \% / \mathrm{my}$ was reported with the ML method (HKY model), which is based on the evolutionary and biogeographical patterns of European cyprinids (Zardoya and Doadrio 1999). Given this rate, the divergence of the two groups dated back to approximately 1.0 million years ago.

Groups I and II were both present in the Kanto Plain; however, the frequency of fish belonging to each group differed among the seven rivers studied (Table 1). Group I was composed of half or more of the fish samples collected from five rivers (NK, KN, OM, TM, and SG). Haplotype H01 composed as much as $96 \%$ (213 of 223) of the sequences belonging to group I. Haplotypes H05 and H06 composed only $3 \%$; therefore, one of the two subclusters in group I represented a minor presence. No single haplotype composed $>6 \%$ of the sequences of group II (127 fish). Group II was found in all seven rivers and included all haplotypes found in KJ and in HN (Table 1). This result reflects that the latter two rivers in the northern Kanto Plain are outside the original distribution range of $Z$. platypus (Miyadi et al. 1976). In contrast, the Naka River, which is located directly south of the Kuji River, was considered the northern boundary of the original distribution range. The composition of the group II haplotypes was heterogeneous at almost all of the sites (Table 1). Two to 11 haplotypes were found at each site and, if any, 1 to 5 haplotypes were unique to each site. However, most of these sites also shared more than half of their haplotypes with other sites. In the Naka and Kinu Rivers, where fish were sampled at six sites, the frequency of group II haplotypes significantly differed between the rivers (Wilcoxon rank-sum test, $W=4.5, P<0.05)$, whereas the frequency did not differ unidirectionally along the course of the rivers. The average frequency was higher in the Kinu River (41\%) than in the Naka River (24\%).

The results of the estimation of the number of populations using the STRUCTURE software are summarized in Table 2. Gene diversities of the Lake Biwa samples are listed in Table 3, and those diversities of the Naka and Kinu Rivers are listed in Table 2 of Takamura 


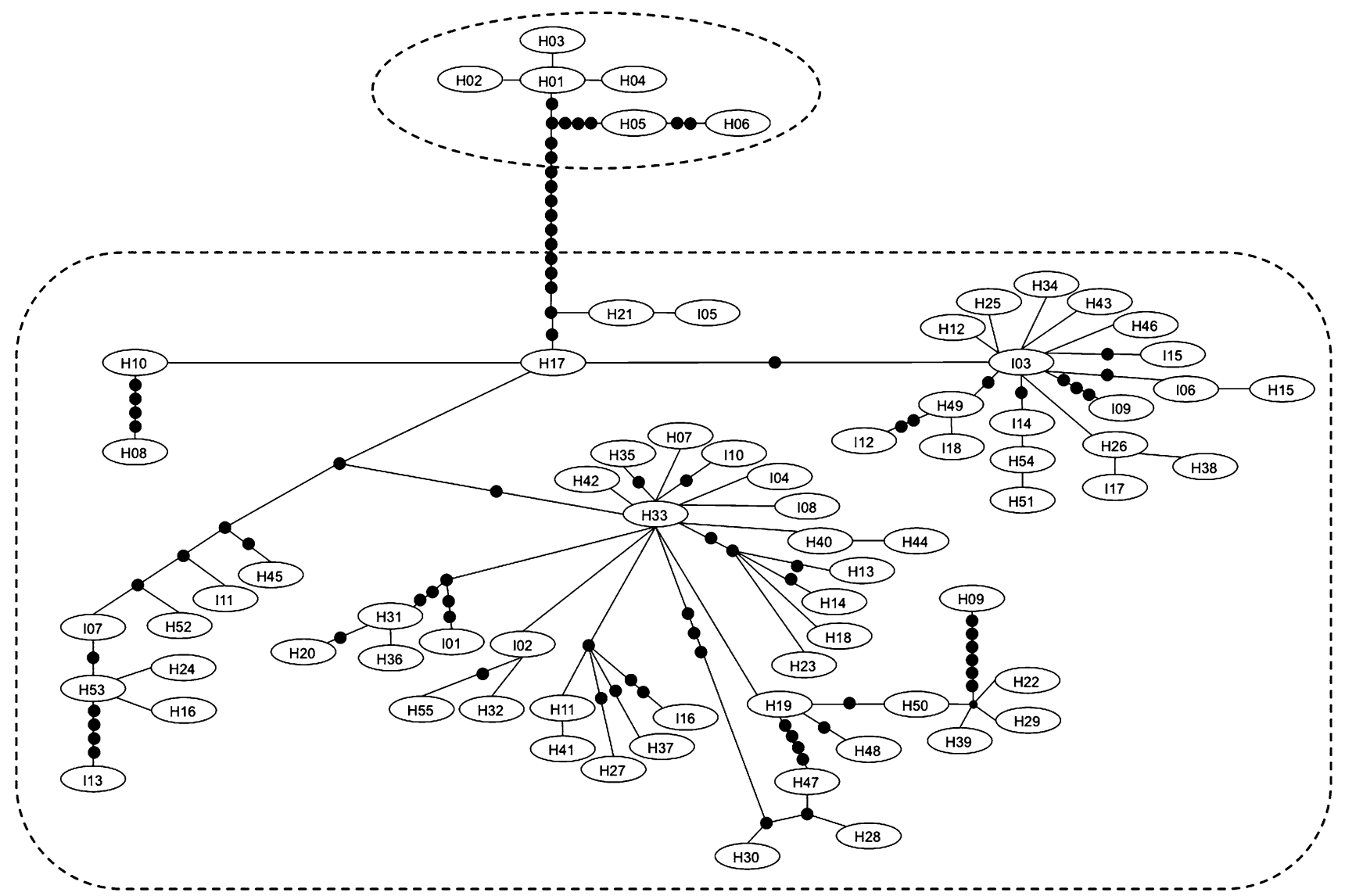

Fig. 2 Statistical parsimony network for 73 haplotypes of Z. platypus mitochondrial haplotype. The names of haplotypes are identical to constructed using the TCS 1.21 software. Each oval represents one

those names in Table S1. Small solid circles represent hypothetical haplotypes. Haplotypes of groups I and II are encircled with dash lines, respectively

\section{Discussion}

(2009). The highest mean Ln P(D) was estimated for $K=2$ under the model with prior population information concerning the Lake Biwa origin, whereas it was estimated for $K=1$ under the model without such information. The criterion $\Delta K$ was highest for $K=2$ under both models; however, this criterion was not available for $K=1$. The difference of the mean $\mathrm{Ln} \mathrm{P}(\mathrm{D})$ between $K=1$ and $K=2$ was subtle under both models; therefore, in the case of $K=2$ (Fig. 4), bar plots of assignment probability were consulted. In both plots, the proportion of the fish assigned to each population of $K=2$ was almost symmetrical in the populations of the Naka and Kinu Rivers. In contrast, the population of Lake Biwa was separable from the populations of the rivers, even under the model without prior information. According to Prichard et al. (2007), when there is no population structure, the proportion of the sample assigned to each population is roughly symmetric, and most individuals are fairly admixed. Thus, the plots suggested that fish of Lake Biwa were assigned to one origin, the lake itself, even without prior population information, and that fish in the rivers were well admixed.
The present survey revealed that two groups of haplotypes occurred in rivers of the Kanto Plain: one of the groups (group I) was dominated by a single haplotype (H01), and the other group (group II) was heterogeneously composed of 58 haplotypes. Group II contained all of the haplotypes we have found from specimens of Lake Biwa. Hayakawa et al. (2009) reported the presence of three phylogroups, East Japan, West Japan, and Kyushu, based on a phylogenetic analysis of the mitochondrial cytochrome $b$ gene. The analysis included sequence data of our six haplotypes (H01-H06). The six haplotypes (H01-H06) belong to East Japan. All of the haplotypes these authors found from Lake Biwa specimens belong to the West-Japan phylogroup (see also Mukai 2010). Both this analysis and our results indicate that haplotypes of group I are native to the Kanto Plain and that those haplotypes of group II were introduced from western Japan, especially Lake Biwa.

It has been concluded that all the 58 haplotypes of group II in the Kanto Plain originated from western Japan. However, it is not necessarily clear whether these 
Fig. 3 Phylogenetic tree of $Z$. platypus haplotypes from rivers of the Kanto Plain and from Lake Biwa, Japan, constructed using the Bayesian method. " $\mathrm{H}$ " haplotypes were found only in the Kanto Plain. "I" haplotypes were found in Lake Biwa but include those haplotypes also found in the Kanto Plain. Reliabilities of clusters are displayed along the branches only on the five major clusters and two subclusters. All other clusters have reliabilities $<50 \%$. Haplotypes of groups I and II are marked with brackets, respectively. The tree is drawn to scale according to evolutionary distances. $N t N$. temmincki (accession no. AF309084) as an outgroup taxon

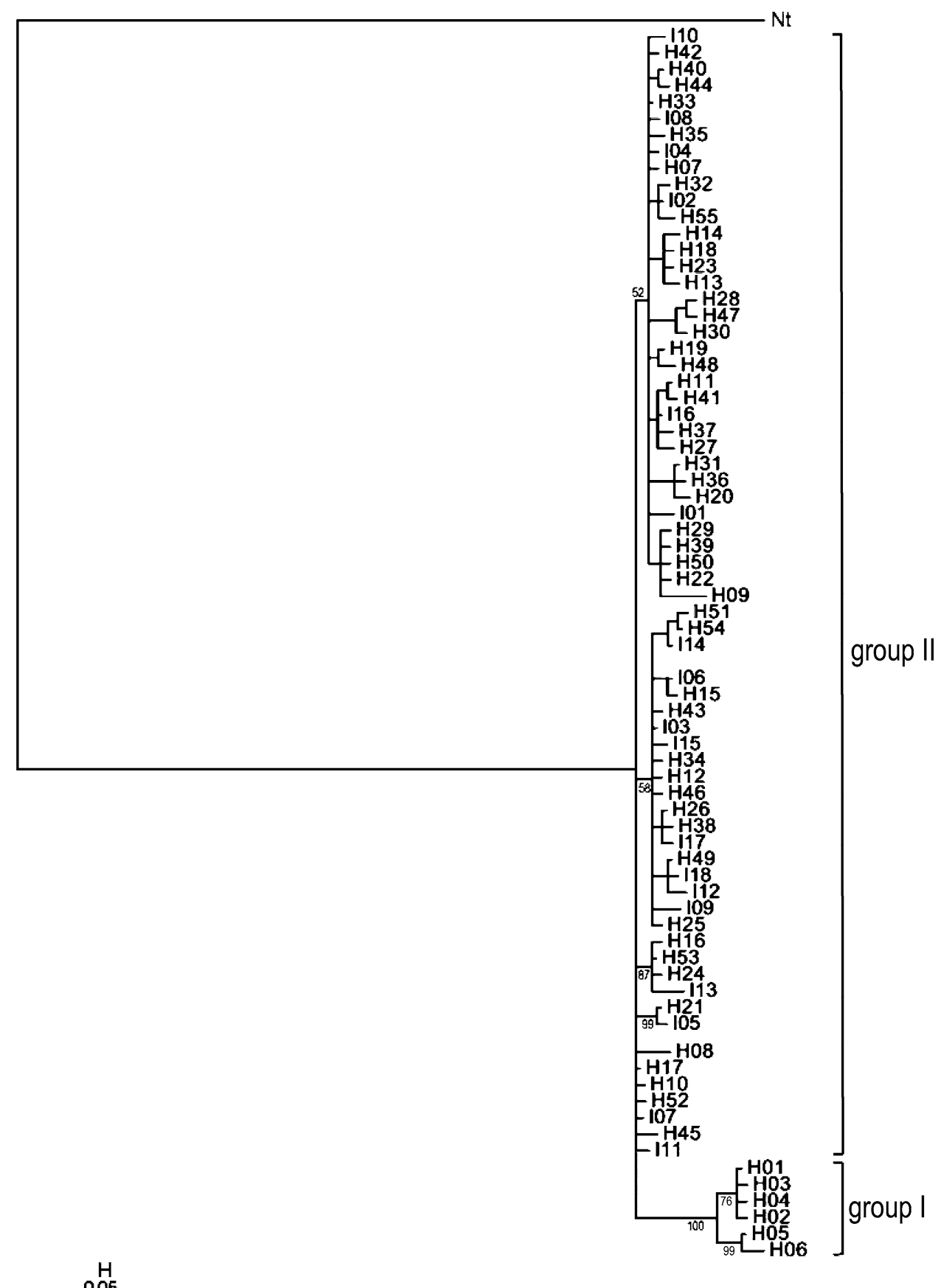

$\underset{0.05}{H}$

\begin{tabular}{llllllll}
\hline PPI & Statistic & $K=1$ & $K=2$ & $K=3$ & $K=4$ & $K=5$ & $K=6$ \\
\hline Yes & mLn P(D) & -8225 & -8148 & -8287 & -9221 & -9324 & -9251 \\
& $\Delta K$ & & 41.79 & 16.89 & 5.59 & 0.93 & 0.18 \\
No & mLn P(D) & -8225 & -8258 & -8877 & $-10,122$ & -9474 & -9576 \\
& $\Delta K$ & & 52.58 & 6.89 & 8.88 & 4.59 & 0.20
\end{tabular}

Simulation results for $K=7,8,9$, and 10 are omitted from the table because these results departed from the results for $K=1,2$, and 3

$P P I$ simulation with prior population information $K$ number of populations estimated, $m L n P(D)$ mean $\log$ transformed posterior probability of $K, \Delta K$ an ad hoc statistic of Evanno et al. (2005) 
Table 3 Gene diversities of the Lake Biwa population based on microsatellite markers

\begin{tabular}{lllllll}
\hline Site & $\mathrm{R}$ & $\mathrm{HO}$ & $\mathrm{HE}$ & $\mathrm{H}-\mathrm{W}$ & $\mathrm{LD}$ & $\mathrm{NA}$ \\
\hline Lake Biwa & $1.9-8.4$ & $0.70(0.33-0.95)$ & $0.70(0.28-0.96)$ & $\mathrm{No}$ & No $^{\mathrm{a}}$ & $0.032-0.286$ \\
\hline
\end{tabular}

$R$ range of allelic richness for each locus per sample size (21 fish), $H O$ observed heterozygosity for all loci and each locus (range), $H E$ expected heterozygosity for all loci and each locus (range), $H$ - $W$ HardyWeinberg equilibrium, $L D$ linkage disequilibrium at all pairs of loci for populations including the Naka and Kinu rivers, $N A$ estimated null allele frequencies for seven loci (range) for populations including the Naka and Kinu Rivers

${ }^{\text {a }}$ No linkage disequilibrium, except for the pair of loci ZD331 and ZD657

(a)

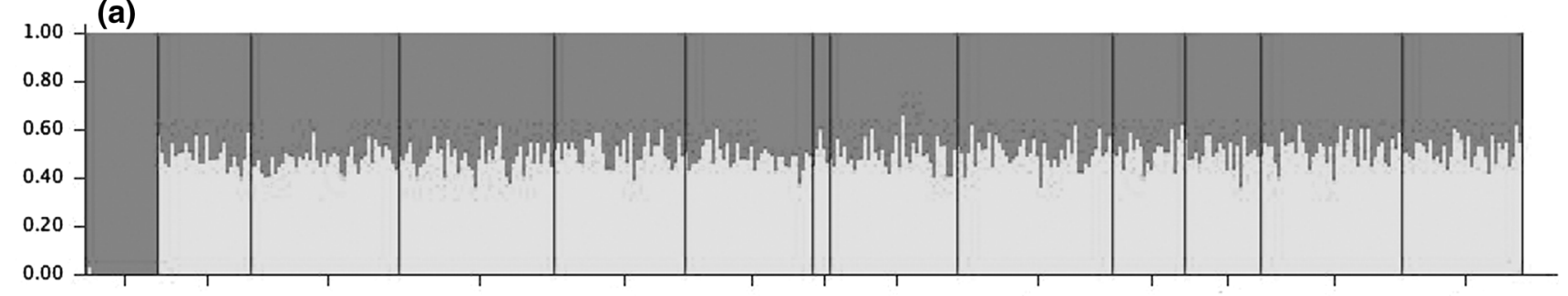

(b)

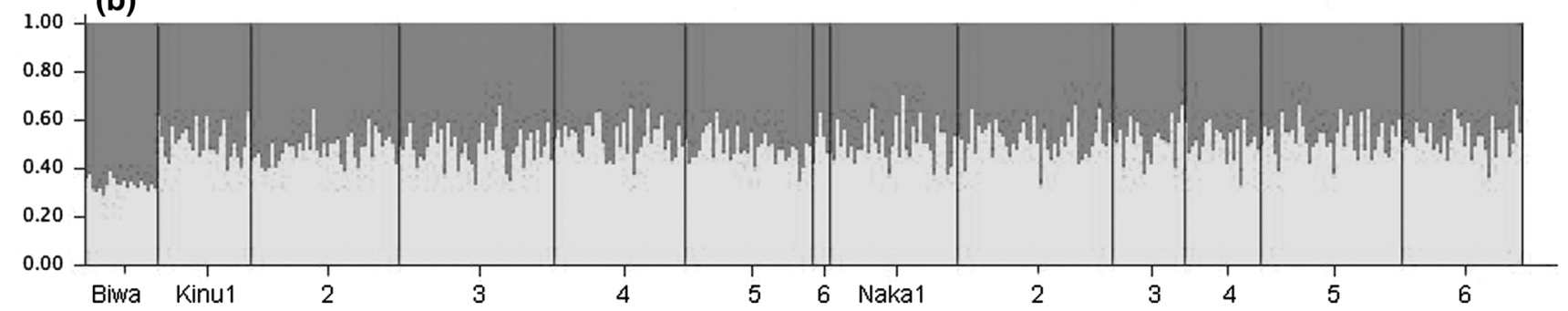

Fig. 4 Bar plots of the assignment probability to two populations $(K=2)$ based on the microsatellite allele frequency for $Z$. platypus in the Naka and Kinu Rivers using the STRUCTURE software. Both

haplotypes have come from Lake Biwa. The 58 haplotypes were far more numerous than nine haplotypes found from both the Kanto Plain and Lake Biwa. First, this is because the number of fish specimens from Lake Biwa was as small as 18 . Second, fish may have also been introduced from other water bodies than Lake Biwa (Mizuguchi 1990). However, the highly heterogeneous haplotype composition in Lake Biwa is also noteworthy. Each of the specimens from the lake had a unique haplotype (18 different haplotypes). Many more haplotypes could be collected from the lake. Because this lake is the largest in Japan and has a wide variety of lakeshore environments, as well as many inflowing rivers and connecting ponds, it is natural that there is a wide spectrum of sequence variation, even in mitochondrial DNA. The genetic variation in the lake itself awaits further analysis.

In an earlier study, populations introduced from Lake Biwa were discriminated from native populations by the mean number of vertebrae (Mizuguchi 1970). However, this morphometric characteristic cannot accurately identify the origin of individual fish because the ranges of vertebra plots were created under the admixture model with correlated allele frequencies $\mathbf{a}$ with and $\mathbf{b}$ without prior population information, respectively. The supposed origin in Lake Biwa is drawn in dark gray

number widely overlap between populations of Lake Biwa and others (Mizuguchi 1970). This difficulty has been overcome with the present molecular phylogenetic approach, and the present result is the first scientific evidence that the introduced $Z$. platypus of Lake Biwa has been established in other freshwater bodies with the presence of a different phylogroup.

Results of the STRUCTURE analysis are fundamentally in accordance with the fact that Z. platypus of Lake Biwa was introduced into rivers of the Kanto Plain. The rather mixed origin estimated for the Lake Biwa population, which was inferred by the model without prior information, might be due to the size homoplasy of microsatellite markers (Balloux and Lugon-Moulin 2002; Avise 2004) realized after a long isolation (approximately 1 million years) between the lake and eastern Japan. The results indicated that introduced fish from Lake Biwa hybridized with native fish and that, currently, individual fish are genetically well admixed, with no clear sign of population structure in some rivers of the Kanto Plain. Given the frequent and massive introduction of fish from Lake Biwa, 
hybridization between native and introduced Z. platypus is probable. In the presence of hybridization, it is less likely to find any phenotypic differences between the groups of mitochondrial DNA haplotypes. At least, the emergence period of larval fish (Takamura 2013) as well as the trophic position of adult fish (Takamura 2009, 2013) is not different between the haplotype groups in the rivers.

The discrimination by mitochondrial DNA phylogeny could lead to false inferences concerning the hybridizing populations. Current patterns of gene flow are often well reflected in neutral genetic loci, such as mitochondrial genes, but not in loci under selective pressures (Karl and Avise 1992; Williams et al. 2002). In mitochondrial genes, the smaller effective population size also strengthens this phenomenon. In the hybridization process, it is often reported that the original genotypes are lost at mitochondrial loci but are retained at nuclear loci. There are such reports on freshwater fishes, e.g., the species of the Japanese threespine stickleback (Orti et al. 1994; Higuchi and Goto 1996; Yamada et al. 2001; Takamura and Mori 2005) and two African cichlids of Neolamprologus fasciatus (Boulenger) and Lamprologus callipterus Boulenger (Nevado et al. 2009), in which the original morphological characteristics are retained. Another noteworthy feature of the hybridization process is that there may have been differences in the hybridization success between female and male introduced fish because introgression by mitochondrial haplotype appeared to be weaker than that by microsatellite markers.

As the long geographical isolation and the lentic environment of the Lake Biwa system might have evolved a certain degree of adaptation to the lacustrine habitat in the Lake Biwa population of Z. platypus (Mizuguchi 1970), more surveys concerning ecological differences among local populations of Z. platypus are required to reveal impacts of intraspecific invasion. For such surveys, local populations not invaded by the Lake Biwa population would be essential. However, the invasion has widely expanded to most of the area in the Japanese islands. Therefore, first, native populations that have not yet been invaded must be located. There is a slim chance that this task can be accomplished; however, this situation emphasizes the importance of measures to predict, find, and prevent the possible cases of intraspecific invasion.

Acknowledgments This work was funded by the National Institute for Environmental Studies of Japan as the special research on invasive species and GMO as well as the Biodiversity Research Program. We are grateful to Yukio Onoda for aid in sample collection from Lake Biwa, Masahiro Akutsu for release records of $P$. altivelis in the Naka and Kinu Rivers, and Suzurei Simamura, Midori Ishitsuka, Yasuko Oikawa, and Natsuko Kondo for genetic analysis.
Open Access This article is distributed under the terms of the Creative Commons Attribution 4.0 International License (http:// creativecommons.org/licenses/by/4.0/), which permits unrestricted use, distribution, and reproduction in any medium, provided you give appropriate credit to the original author(s) and the source, provide a link to the Creative Commons license, and indicate if changes were made.

\section{References}

Allendorf FW, Leary RF, Spruell P, Wenburg JK (2001) The problems with hybrids: setting conservation guidelines. Trends Ecol Evol 16:613-622

Avise JC (2000) Phylogeography. Harvard University Press, London, p 447

Avise JC (2004) Molecular markers, naural history, and evolution, 2nd edn. Sinauer, Massachusetts, p 684

Balloux F, Lugon-Moulin N (2002) The estimation of population differentiation with mcrosatellite markers. Mol Ecol 11:155-165

Bennett SN, Olson JR, Kershner JL, Corbett P (2010) Propagule pressure and stream characteristics influence introgression: cutthroat and rainbow trout in British Columbia. Ecol Appl 20:263-277

Clement M, Posada D, Crandall K (2000) TCS: a computer program to estimate gene genealogies. Mol Ecol 9:1657-1660

Darriba D, Taboada GL, Doallo R, Posada D (2012) jModelTest 2: more models, new heuristics and parallel computing. Nat Methods 9:772

Ecological Society of Japan (2002) Handbook of Alien Species in Japan [Gairai-shu handobukku]. Chijin Shokan, Tokyo, p 390 (in Japanese)

Evanno G, Regnaut S, Goudet J (2005) Detecting the number of clusters of individuals using the software STRUCTURE: a simulation study. Mol Eco 14:2611-2620

Gaither MR, Bowen BW, Toonen RJ, Planes S, Messsmer V, Earle J, Ross Robertson D (2010) Genetic consequences of introducing allopatric lineages of Bluestriped Snapper (Lutjanus kasmira) ot Hawaii. Mol Ecol 19:1107-1121

Goudet J (1995) Fstat version 1.2: a computer program to calculate Fstatistics. J Heredity 86:485-486

Gozlan RE, Britton JR, Cowx I, Copp GH (2010) Current knowledge on non-native freshwater fish introductions. J Fish Biol 76:751-786

Guindon S, Gascuel O (2003) A simple, fast and accurate method to estimate large phylogenies by maximum-likelihood. Syst Biol 52:696-704

Hansen MM, Fraser DJ, Meier K, Mensberg KD (2009) Sixty years of anthropogenic pressure: a spatio-temporal genetic analysis of brown trout populations subject to stocking and population declines. Mol Ecol 18:2549-2562

Hayakawa A, Takamura K, Nakajima J, Kawaguchi Y, Onikura N, Mukai T (2009) Phylogeographical analysis of within-country transplantation of a freshwater fish Zacco platypus in Japanese Isles [Nihonrettou ni okeru oikawa no keitouchiri to kokunaiishoku no jittai]. In: Proceedings of the 56th Annual Meeting of Ecological Society of Japan, p 402 (in Japanese)

Higuchi M, Goto A (1996) Genetic evidence supporting the existence of two distinct species in the genus Gasterosteus around Japan. Environ Biol Fish 47:1-16

Huang MT, Tsao EHS, Yu AHT (2003) Isolation and cross-species amplification of microsatellite loci in the freshwater minnow Zacco pachycephalus (Teleostei: Cyprinidae) for diversity and conservation genetic analysis. Mol Ecol Note 3:567-569 
Huelsenbeck JP, Ronquist F (2001) MRBAYES: bayesian inference of phylogeny. Bioinformatics 17:754-755

Karl SA, Avise JC (1992) Balancing selection at allozyme loci in oysters: implications from nuclear RFLPs. Science 256:100-102

Kawabe T (1994) Geological history of Lake Biwa [Biwa-ko no oitachi]. In: Research Group for Natural History of Lake Biwa (ed) The natural history of Lake Biwa [Biwako no shizenshi]. Yasaka Shobo, Tokyo, pp 25-72 (in Japanese)

Kawai T, Kawanabe H, Mizuno N (1980) Freshwater organisms of Japan, ecology of invasion and disturbance [Nihon no tansuiseibutsu, shinryaku to kakuran no seitaigaku]. Tokai University Publishing, Tokyo, p 194 (in Japanese)

Kuwahara M, Takahashi H, Kikko T, Kurumi S, Iguchi I (2012) Introgression of Oncorhynchus masou subsp. (Biwa salmon) genome into lake-run O. m. ishikawae (Amago salmon) introduced into Lake Biwa, Japan. Ichthyol Res 59:195-201

Lever C (1996) Naturalized Fishes of the World. Academic Press, London $408 \mathrm{pp}$

Ma GC, Watanabe K, Tsao HS, Yu HT (2006) Mitochondrial phylogeny reveals the artificial introduction of the pale chub Zacco plaltypus (Cyprinidae) in Taiwan. Ichthyol Res 53:323-329

Miyadi D (1962) Stories of the ayu fish [Ayu no hanashi]. Iwanami Shoten, Tokyo, p 226 (in Japanese)

Miyadi D, Kawanabe H, Mizuno N (1976) Coloured illustrations of the freshwater fishes of Japan [Genshoku nihon tansui gyorui zukan]. Hoikusha Publishing, Osaka, p 462 (in Japanese)

Mizuguchi K (1970) Reproductive ecology of the pale chub [Zacco platypus $(\mathrm{T} \& \mathrm{~S})]$ and a few morphological variations accompanying the artificial expansion of its distribution range [Oikawa no hanshoku seitai to bunpuiki no kakudai ni tomonau nisan no keishitsu no hen-i]. Dissertation 102306, University of Tokyo, Tokyo, (in Japanese)

Mizuguchi K (1990) Dispersal of the pale chub, Zacco platypus (Temminck et Schlegel), in Japan [Oikawa no nihon ni okeru bunpuiki no kakudai]. Rep Tokyo Univesity Fisheries 25:149-169 (in Japanese)

Mizuno N, Kawanabe H, Miyadi D, Mori S, Kodama HN, Ohgushi R, Kusakabe A, Huruya YY (1958) Studies on the life of river fish I. The life history of four cyprinid species [Kawa no sakana no seikatsu I. Koika yonshu no seikatsushi wo chuushin ni shite]. Contribution Physiol Ecol, Kyoto University 81:1-48 (in Japanese)

Mori S, Miura T (1990) List of plant and animal species living in Lake Biwa. Memoirs of the Faculty of Science, Kyoto University, Biology 14:13-32

Mukai T (2010) Alien species from own country: the genetic diversity of the freshwater fish "Oikawa" is declining [Oikawa, kokunaisan demo gairaishu, idenshi no tayousei ga gensho]. Nat Conserv 517:27 (in Japanese)

National Land with Water Information Data Management Center (2014) River Enivromental Database [Kasen-kankyo database]. http://mizukoku.nilim.go.jp/ksnkankyo/index.html. Cited 25 June 2014 (in Japanese)

Nature Conservation Committee of Ichthyological Society of Japan (2005) Guideline for fish release to conserve biodiversity [Seibutsu- tayousei no hozen wo mezashita gyorui no horyugaidorain]. http://www.fish-isj.jp/iin/nature/guideline/2005.html. Cited 25 June 2014 (in Japanese)

Nevado B, Koblmuller S, Sturmbauer C, Snoeks J, Usano-Alemany J, Verheyen E (2009) Complete mitochondrial DNA replacement in a Lake Tanganyika cichlid fish. Mol Ecol 18:4240-4255

Orti G, Bell MA, Reimchen TE, Meyer A (1994) Global survey of mitochondrial DNA sequences in the threespine stickleback: evidence for recent migrations. Evolution 48:608-622
Perdices A, Cunha C, Coelho MM (2004) Phylogenetic structure of Zacco platypus (Teleostei, Cyprinidae) populations on the upper and middle Chang Jiang (Yangtze) drainage inferred from cytochrome $b$ sequences. Mol Phylogen Evol 31:192-203

Prichard JK, Stephens M, Donnelly P (2000) Inference of population structure using multilocus genotype data. Genetics 155:945-959

Prichard JK, Wen X, Falush D (2007) Documentation for structure software: Version 2.2. http://pritchardlab.stanford.edu/software/ structure2_2.html. Accessed 25 June 2014

Raymond M, Rousset F (1995) Genepop (version 1.2): population genetics software for exact tests and ecumenicism. J Hered $86: 248-249$

Rousset F (2008) Genepop'007: a complete reimplementation of the Genepop software for Windows and Linux. Mol Ecol Resour 8:103-106

Saitoh K, Kobayashi T, Ueshima R, Numachi K (2000) Analyses of mitochondrial and satellite DNAs on spined loaches of the genus Cobitis from Japan have revealed relationships among populations of three diploid-tetraploid complexes. Folia Zool 49(Suppl 1):9-16

Takahashi S, Okazaki T (2002) A new lentic form of the "yoshinobori" species complex, Rhinogobius spp. form Lake Biwa, Japan, compared with lake-river migrating Rhinogobius sp OR. Ichthyol Res 49:333-339

Takamura K (2009) Population structuring by weirs and the effect on trophic position of a freshwater fish Zacco platypus in the middle reaches of Japanese rivers. Fundam Appl Limnol 174:307-315

Takamura K (2013) Intraspecific invasion of Zacco platypus from Lake Biwa to the Kanto Plain [Biwa-ko kara kanto no kasen eno oikawa no teichaku]. In: Nature Conservation Comittee of Ichthyological Society of Japan (ed) Domestic alien fishes: Hidden threats to biodiversity [Mienai kyoui kokunai gairaigyo]. Tokai University Press, Hatano, pp 85-100 (in Japanese)

Takamura K, Mori S (2005) Heterozygosity and phylogenetic relationship of Japanese threespine stickleback (Gasterosteus aculeatus) populations revealed by microsatellite analysis. Conserv Genet 6:485-494

Tamura K, Nei M (1993) Estimation of the number of nucleotide substitutions in the control region of mitochondrial DNA in humans and chimpanzees. Mol Biol Evol 10:512-526

Tamura K, Dudley J, Nei M, Kumar S (2007) MEGA4: molecular evolutionary genetics analysis (MEGA) software version 4.0. Mol Biol Evol 24:1596-1599

The R Foundation for Statistical Computing (2005) R version 2.2.0. Vienna University of Technology, Vienna

Watanabe K, Mori S, Nishida M (2003) Genetic relationships and origin of two geographic groups of the freshwater threespine stickleback, 'Hariyo'. Zool Sci 20:265-274

Williams ST, Jara J, Gomez E, Knowlton N (2002) The marine IndoWest Pacific break: contrasting the resolving power of mitochondrial and nuclear genes. Integ Compar Biol 42:941-952

Yamada M, Higuchi M, Goto A (2001) Extensive introgression of mitochondrial DNA found between two genetically divergent forms of threespine stickleback, Gasterosteus aculeatus, around Japan. Environ Biol Fish 61:269-284

Yokoyama R, Yamamoto S (2012) Freshwater sculpin dwelling in Lake Chuzenji, Nikko, Kanto District, Japan, is identified as Utsusemikajika, Cottus reinii, unintentionally introduced from Lake Biwa. Ichthyol Res 59:389-393

Yoshiyasu K (1973) Starch-gel electrophoresis of hemoglobins of freshwater salmonid fishes in Southwest Japan-II. Genus Oncorhynchus (Salmon). B Jap Soc Sci Fish 39:97-114

Zardoya R, Doadrio I (1999) Molecular evidence on the evolutionary and biogeographical patterns of European cyprinids. J Mol Evol $49: 227-237$ 